\title{
Design of Automatic Cooling Power Hacksaw Machine for Multipurpose Applications
}

\author{
Ikpe Aniekan E. ${ }^{1 a^{*}}$ and Owunna Ikechukwu ${ }^{1 b}$ \\ ${ }^{1}$ Department of Mechanical Engineering, University of Benin, Benin City, P.M.B. 1154, Nigeria \\ "Email: ${ }^{a}$ ikpeaniekan@gmail.com, ${ }^{b}$ ikechukwu.owunna@uniben.edu
}

\begin{abstract}
This study involves a comparative analysis of a designed automatic cooling power hacksaw machine and manual cooling power hacksaw machine in a local sawmill where coolant is applied manually by the operator. The automatic cooling power hacksaw machine took an average time of $40 \mathrm{~s}$ to cut an average mass of $5.9 \mathrm{~kg}$ with average Specific Mechanical Energy (SME) of $29 \mathrm{kj} / \mathrm{kg}$ and average cutting speed of $270 \mathrm{rpm}$. However, the manual cooling hacksaw machine took an average time of $53 \mathrm{~s}$ to cut the same average mass of $5.9 \mathrm{~kg}$ with average SME of $42 \mathrm{kj} / \mathrm{kg}$ and average cutting speed of $269 \mathrm{rpm}$. The basic idea behind SME was to determine the energy going into the cutting operation process per unit mass of timber in form of work from the motor. From the above stated results, the automatic cooling hacksaw machine designed in this study took less time, less SME and slightly higher cutting speed to cut the same quantity of timber than the manual cooling hacksaw machine. Compared to the manual cooling power hacksaw, the automatic cooling power hacksaw machine is obviously more efficient in terms of time and energy savings.
\end{abstract}

Keywords- Design, Hacksaw, Cutting speed, Power, Torque, Time.

\section{INTRODUCTION}

While the importance of manual hacksaw as a simple hand tool for cutting metals and non-metals cannot be overemphasized, the manual labour involved in its operation is highly cumbersome and tiring when a great deal of cutting has to be carried out on materials with thick and wide dimensions. This may have led to the idea of applying power to the principle of saws originally designed for executing various cutting operation that requires the use of simple hand tools. Prior to the incorporation of power driving mechanisms to any machine, power transmission at appropriate speed and torque must be considered in the original design or design modification of such machine. However, power hacksaw as the name implies is a type of hacksaw that is powered by electric motor with low speed, and this sometimes require reduction from the normal motor speed to a moderately low speed that is suitable enough to drive the sawing machine parts $[1,2]$. Power hacksaws are widely applicable in operations that require cutting large dimension materials such as metals, wood, plastics, glasses etc. [3, 4].

Technicians and craftsmen would agree to the fact that cutting of solid shafts or rods with diameters exceeding $20 \mathrm{~mm}$ thickness is a very difficult task to be achieved with normal hand held hacksaw which is where the power hacksaw machine comes into play [5]. The power hacksaw machine is a piece of equipment that is designed to cut material to desired length and contours, there by simplifying the cutting process for the machine operator by essentially saving time, energy and material wastage $[6,7]$. In other words, power sawing machine is faster, easier and more accurate in terms of precision cutting than hand sawing and is mainly used in producing accurate angular cutting as well as square or metered cutting on a workpiece [8]. The operation principles of power hacksaw and the bandsaw which are the two commonly used sawing machines involve running a blade with series of teeth on its edge through a given workpiece to cut a narrow opening into a workpiece [9]. 
The saw blade is selected based on the thickness of material intended for cutting with special attention to the shape of the saw blade, teeth spacing and clearance; as materials wider than the optimum blade width can diminish the cutting accuracy and rigidity of blade, thereby resulting in blade deflection [10]. Blade deflection is caused by one of the following; non-vertical blade, non-rigid arm, sideways arm movement, random blade dullness, material hard spots etc.

Some sawing machine operations are achieved with dry cutting machines (also referred to as ecological machining); that is, they are not designed for use with liquid coolants [11]. As a result of that, the machine operators sometimes stop operation for few minutes to apply coolant on the sawing blade, and this interception usually result in downtime depending on the interception time. However, some indications during cutting operation such as blue, brown, or burned chips implies the lack of coolant, insufficient cooling, incorrect coolant or incorrect coolant feed. The heat generated during cutting may increase the blade temperature, reduce its mechanical strength, thereby causing plastic deformation in the shear zone of the cutting blade and possible failure such as braking of saw blade, curved cutting, teeth braking, blunt effects etc. [12, 13]. For example, Danielson and Schajer [14] measured saw blade temperature gradient and lateral movement on a circular gang edger under normal sawmill operation. The result indicated that saw blade over-tensioning, saw heating due to inadequate guide cooling and guide movement during sawing are the three common factors that causes increasing blade temperature and unwanted vibration during wood cutting process.

The importance of applying coolant on the sawing blade is to prevent excessive heat, reduces friction between the workpiece and the sawing blade, reduce the thermal conductivity and thermal expansion of the sawing blade during operation (A large thermal expansion coefficient of a metal implies that coolants is required), prevents chip-clogged teeth, prevent breakage and excessive wear, increases blade life and above all save time, energy and material wastage [2]. Soluble oil based coolant or water-soluble synthetic coolant, when mixed with water to form emulsions, are used for these machines. This type of coolant has proven very satisfactory for sawing operation where cooling is an essential factor. Most manufacturers of water oil emulsion coolants add a rust inhibitor to the solution to prevent rusting caused by water content present in the coolant [15].

In contribution to research and development, several studies have been carried out on the power hacksaw machine. For example, Parmar et al. [16] reviewed the design and fabrication of a four power adjustable stroke hacksaw, and found out that the rate of cutting a given size of material can be increased by increasing the motor power and the dimension of eccentric cam. It was also indicated in the review that automatic hoisting mechanism for frames during cutting operation can be achieved using hydraulic piston and cylinder. Sreejith et al. [17] Designed, fabricated and investigated the work performance of a pedal driven hacksaw machine. The experiment which was carried out on a workpieces of a plywood indicated that cutting depth of about $17 \mathrm{~mm}$ can be achieved in one cycle of strokes for around 100rpm, thereby, minimizing the energy input compared to hand saws and the cost of utility bill compared to power hacksaws. Using a single phase electric motor of $120 \mathrm{~W}$ and $920 \mathrm{rpm}$ specification, Kumar et al. [18] designed and fabricated a double acting hacksaw machine. The machine was tested on mild steel shaft of $25 \mathrm{~mm}$ diameter with 12 inch length, and it took a duration of 240 seconds to cut the shaft with a new hacksaw blade.

In this context, a power hacksaw system equipped with coolant attachment is designed and the cutting time for various masses of timber will be observed and compared to the hacksaw machine in a local sawmill without cooling compartment (in which case the operator applies coolant manually).

\section{MATERIALS AND METHOD}

\subsection{Methodology}

Evaluation of the machine performance was carried out for both automatic and manual cooling hacksaw machine using timber of different mases. Stop watch was used to determine the total time required to cut each mass of timber. Energy equation was applied in the determination of Specific 
Mechanical Energy (SME). Existing equation was adopted for determining the cutting speed for the hacksaw incorporated with automatic cooling system and the same machine in a local sawmill where the coolant is applied manually to the saw blade. Thermal analyses was also considered to show the theoretical relationship of the heat transfer process between the sawing blade and the workpiece. 3D design drawing was generated for the automatic cooling hacksaw machine which showed clearly the cooling devices. Detailed design for the hack saw machine was carried out based on the design requirements shown in Table 1.

\subsection{Design Specification}

i. The automatic hacksaw design is expected to operate within a rotating speed of $1425 \mathrm{rpm}$

ii. It must not deliver a crushing force greater than $220 \mathrm{~N}$

iii. The crushing power must not exceed $4 \mathrm{hp}$

iv. Determination of approximate length of the belt $(\mathrm{mm})$

v. The required toque must not fall below $80 \mathrm{Nm}$

vi. Estimation of belt tension

Table 1: Design Requirements

\begin{tabular}{cl}
\hline Considerations & Description \\
\hline Power & Low speed 230V, 375W \\
Requirement & single phase electric motor \\
& and an approved 3 pin safety \\
& plug.
\end{tabular}

Belt and Pulley A belt on the driving pulley is rotated by the motor shaft, whereas, the other end of the belt is coupled to the driven pulley groove which transmits the rotary motion of the motor to the gear via a shaft.

Shaft

Hacksaw main frame

Hacksaw Blade
APEX 6500
Coolant in the electric motor and other parts of the hacksaw that transmits power from one part to the other.

houses the hacksaw and connect other parts of the machine to one another.

12 inch flat and flexible piece of metal with $350 \times 32 \times 1.60$ dimension, designed with teeth for cutting of workpiece.

APEX 6500 is a moderate to heavy duty synthetic coolant.
Material

Grey cast Iron

A15.5 Classical V-Belt made from Rubber cushion, Polyester cable cord as reinforcement and rubber impregnated woven cotton-polyester fabric. Pulley designed with Cast Iron.

A rotating circular bar found 0.26 carbon steel (B5

A rigid metal framework that Mild steel bar It has a superior oil rejecting qualities. Formulated with

High speed tungsten steel or high speed molybdenum steel

water-soluble synthetic coolant

\section{Justification}

Will enable smooth operation, optimal performance and longevity of the hacksaw machine

Cushions shock loads during service condition of the machine, reduces noise, dampens out and isolates the effect of vibration, can be installed and removed with ease.

Better absorbs shear force and compressive force. High strength, wear resistant, machinable and suitable for torque transmission.

Provides rigidity and support for the machine, prevents minimizes vibration, prevents failure caused by fatigue, positions the saw parallel to the line of travel.

Easily cuts large sections of metal or plastic, shafts and rods. Capable of cutting solid shafts or rods of diameters more than $15 \mathrm{~mm}$.

Ensures that the blade teeth and material in the cutting area do not overheat. Prevents abrasion of the blade teeth. 
extensively high lubricity for high speed machining operation with high feed rates. APEX 6500 runs very clean and is low foaming in hard and soft water applications.

Spur Gear A piece of equipment designed with teeth parallel to the axis of rotation, and used to transmit rotary motion between parallel shafts.
Reduce the motor speed for optimal operation, and also transmit its rotary motion to reciprocating motion of the hack saw blade.

\subsection{Belt and Pulley}

In this context, the belt is a flexible and elastic machine element usually coupled to another machine element known as pulley, and used in conveying systems and in power transmission over relatively long distance. The drive employed in this design for power transmission from an electric motor is the v-belt (Type-A) drive as shown in Figure 1. A V-belt consists of an endless flexible belt that transmits power by contacting and gripping the pulleys [19].

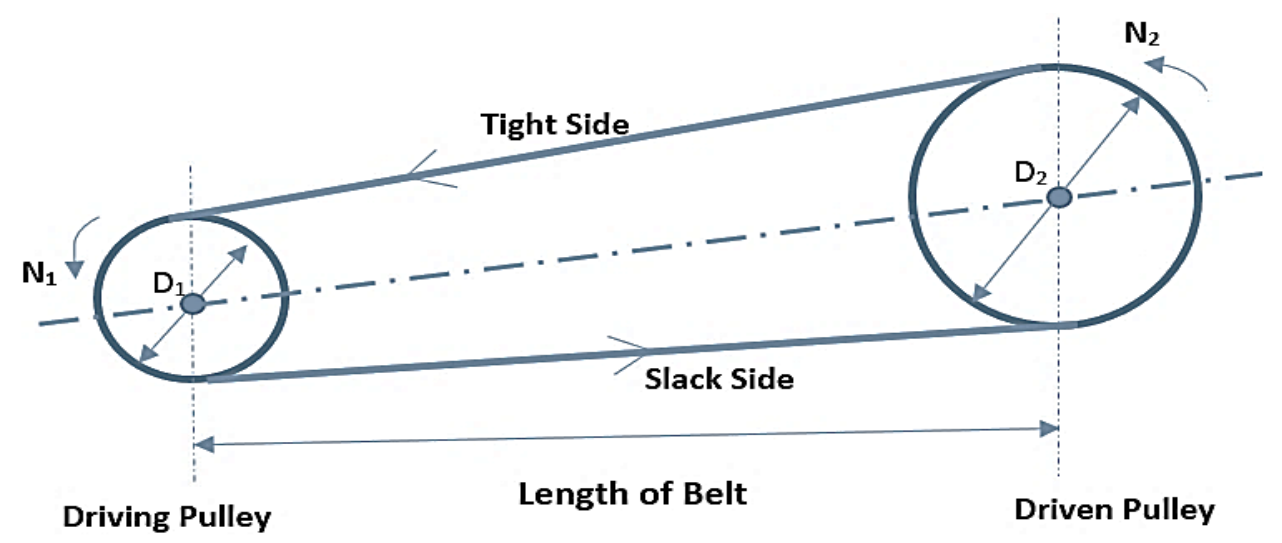

Figure 1: Type-A Classical V-belt Drive

\subsection{Determination of Shaft Speed}

As shown in Figure 1, the transmission system is a V-belt transmitting power via a pulley. Thus, the pulley speed can be determined using the general formula given in equation (1) [20].

$\frac{\mathrm{D}_{1}}{\mathrm{D}_{2}}=\frac{\mathrm{N}_{2}}{\mathrm{~N}_{1}}$

Where, $\mathrm{D} 1=$ diameter of the driver $=50 \mathrm{~mm}=0.05 \mathrm{~m}, \mathrm{D} 2=$ diameter of the driven $=150 \mathrm{~mm}=0.15 \mathrm{~m}$, $\mathrm{N} 1=$ speed of the driver $=1425 \mathrm{rpm}, \mathrm{N} 2=$ speed of the driven $=$ ?

From equation 2, $\mathrm{N}_{2}$ (Rotational speed of the driven pulley) can be calculated using the expression given in equation (2)

$\mathrm{N}_{2}=\frac{\mathrm{D}_{1} \mathrm{~N}_{1}}{\mathrm{D}_{2}}$

$\mathrm{N}_{2}=\frac{50 \times 1425}{150}=475 \mathrm{rpm}$

Velocity ratio $=\mathrm{N}_{1}: \mathrm{N}_{2}=1: 3$ 


\subsection{Determination of Length of Belt}

The formula for determining the length of the belt drive is given by equation (3);

$\mathrm{L}=2 \mathrm{C}+1.57\left(\mathrm{D}_{2}+\mathrm{D}_{1}\right) \frac{\left(\mathrm{D}_{2}-\mathrm{D}_{1}\right)^{2}}{4 \mathrm{C}}$

$\mathrm{L}=2(448)+1.57(240+120) \frac{(240-120)^{2}}{4(448)}=1461 \mathrm{~mm}$

\subsection{Determination of the Belt Contact Angle}

The belt contact angle is given by equation (4);

$\sin \beta=\frac{\mathrm{R}-\mathrm{r}}{\mathrm{C}}$

Where, $\mathrm{R}=$ radius of the large pulley, $\mathrm{r}=$ radius of the smaller pulley, $\mathrm{C}=$ centre distance

$$
\beta=\sin ^{-1}\left(\frac{120-60}{448}\right)=7.69^{\circ}
$$

\subsection{Determination of lap Angle}

Angles of Wrap for the Pulleys are given by equation (6) and (7);

$\alpha_{1}=180-2 \sin ^{-1}\left(\frac{R-r}{C}\right)$

$\alpha_{2}=180+2 \sin ^{-1}\left(\frac{R-r}{C}\right)$

Where, $\alpha_{1}$ is the angle of wrap for the driving pulley, $\alpha_{2}$ is the angle of wrap for the driven pulley, $\alpha_{1}=180-2 \beta$

$$
=180-(2 \times 7.69)=164.62^{\circ}
$$

Converting the angle from degree to radian;

$164.62^{\circ} \times \frac{\pi}{180^{\circ}}=2.87 \mathrm{rad}$

$\alpha_{2} 180+2 \beta$

$\alpha_{2}=180+(2 \times 7.69)=195.38^{\circ}$

$\alpha_{2}=3.42 \mathrm{rad}$

\subsection{Determination of Tension $\left(T_{1}\right)$ in the Tight Side of the Belt}

$\mathrm{T}_{1}=$ Cross sectional area of belt $*$ maximum stress in belt

Cross-sectional area $=$ width $\mathrm{x}$ thickness $=\mathrm{b} \times \mathrm{t}=13 \mathrm{~mm} \times 8 \mathrm{~mm}$

$=104 \mathrm{~mm}^{2}=104 \times 10^{-6} \mathrm{~m}^{2}$

Maximum stress in belt is given as $1.5 \times 106 \mathrm{~N} / \mathrm{m}^{2}$

For a factor of safety of 2.5

$\mathrm{T}_{1}=\left(104 \times 10^{-6} \times 1.5 \times 10^{6} \times 2.5\right)=390 \mathrm{~N}$

\subsection{Determination of tension of the slack side of the belt}

$\frac{\mathrm{T}_{1}-m v^{2}}{\mathrm{~T}_{2}-m v^{2}}=\mathrm{e}^{\left(\frac{\mu \theta}{\sin \beta}\right)}$ 
Where, $T_{1}$ is the tension in the tight side of belt $=390 \mathrm{~N}, \mathrm{~T}_{2}$ is the tension in the slack side of belt $=$ ?, $\mathrm{m}$ is the mass per unit length of belt $=0.104 \mathrm{~kg}, \mathrm{~V}$ is the linear velocity of belt $=355.3 \mathrm{rpm}, \theta$ is the groove angle $=38^{\circ}, \mu$ is the coefficient of friction (assumed) $=0.3$

$T_{2}=\frac{390-36.95}{T_{2}-36.95}=e^{\left(\frac{0.3 \times 38}{\sin 7.69}\right)}$

$\mathrm{T}_{2}=154.27 \mathrm{~N}$

\subsection{Cutting power requirement}

The power required by the hacksaw to cut the workpiece given by equation (12);

$\mathrm{P}=\mathrm{FV}$

Where, $\mathrm{P}=$ power to turn the shaft, $\mathrm{V}=$ speed

Force $(\mathrm{F})=$ Mass $\mathrm{x}$ acceleration due to gravity $(\mathrm{g})$

$\mathrm{g}=9.8 \mathrm{~m} / \mathrm{s}^{2}$

Therefore, Mass of shaft $=3.2 \mathrm{~N}$, Mass of saw blade $=0.130$, Mass of plunger $=1 \mathrm{~N}$, Mass of the gear $=6 \mathrm{~N}$, Mass of coolant cylinder $=1.6 \mathrm{~N}$, Mass of weight $=14 \mathrm{~N}$.

Total mass $=3.2+0.130+1+6+1.6+14=25.9 \mathrm{~N}$

Substituting the total mass into equation (13) will give;

$\mathrm{F}=25.9 \times 9.8=253.8 \mathrm{~N}$

$V=\frac{\pi D N}{60}$

Where, $V=$ Speed, $D=$ Diameter $=150 \mathrm{~mm}=0.15 \mathrm{~m}, \mathrm{~N}=$ Speed in revolution per minute $=1425 \mathrm{rpm}$. Substituting the above values into equation 12 , the power required by the hacksaw to cut the workpiece is given by equation (15)

$P=\frac{F \pi D N}{60}$

$P=\frac{253.8 \times 3.142 \times 0.15 \times 1425}{60}=2840.9$ watts

But,

$1 \mathrm{hp}=750$ watts

Thus,

$2840.9 \mathrm{watts}=3.78 \mathrm{hp}$

Considering a safety factor of 1.2 , the power required for cutting a given workpiece is approximately 4hp. This implies that the hacksaw machine will require $4 \mathrm{hp}$ for proper cutting. DC motor was considered in this design to produce the required torque needed to prevent deflection of the saw blade. A simple formula for the blade deflection is given by equation (16)

$$
Y_{\max }=\frac{1 W L^{\underline{3}}}{48 E I}
$$

Where $\mathrm{Y}=$ Blade deflection, $\mathrm{W}=$ Load on blade, $\mathrm{L}=$ Spacing on Guides, $\mathrm{E}=$ Modulus of elasticity and $\mathrm{I}=$ Moment of inertia.

\subsection{Determination of torque}

The torque is obtained from the formula given by equation (17);

$T=F l$ 
Where, $\mathrm{T}=$ Torque, $\mathrm{F}=$ Force, $\mathrm{L}=$ Length of saw blade

Therefore;

$T=253.8 \times 0.350=88.8 \mathrm{Nm}$

The Torque of motor is increased by transmission of power to a pulley by belt transmission.

\subsection{Thermal Analysis}

Heat is generally transferred across the boundary of systems in three ways through conduction, convection and radiation. In this case, the heat transfer between the sawing blade and workpiece on application of coolant can be explained empirically by Fourier's law of conduction which states that the rate of heat flowing through a single homogeneous solid is directly proportional to the surface area (A) of the section at right angles to the direction of heat flow and to the change of temperature $(\mathrm{d} t)$ with respect to the length of the path of the heat flow [21]. Applying Fourier's law to a thin sawing blade in operation with thickness $\mathrm{d} x$ and surface area $\mathrm{A}$, the rate of heat flow $(\dot{Q})$ is given by equation (18) and (19);

$\dot{Q} \alpha A \frac{\mathrm{d} t}{\mathrm{~d} x}$

Or

$$
\dot{Q}=-\lambda A \frac{\mathrm{d} t}{\mathrm{~d} x}
$$

Where $\lambda$ is the thermal conductivity of the sawing blade material. By integration, equation (19) can be written as expressed in equation (20) and (21);

$$
\int_{0}^{x} \dot{Q} d x=-\int_{t_{1}}^{t_{2}} \lambda A \mathrm{~d} t
$$

Or

$\dot{Q x}=-A \int_{t_{1}}^{t_{2}} \lambda \mathrm{d} t$

These equations can be solved when the variation for thermal conductivity $(\lambda)$ of the saw blade material and the range of temperature (t) at which the hacksaw cuts a given workpiece is known. However, specific value for thermal conductivity of most solids is approximately constant over a wide range of temperatures, and therefore $\lambda$ can be taken as constant,

That is,

$$
\dot{Q x}=-A \lambda \int_{t_{1}}^{t_{2}} \mathrm{~d} t
$$

Or

$$
\dot{Q}=-\frac{\lambda A}{x}\left(t_{2}-t_{1}\right)=\frac{\lambda A}{x}\left(t_{1}-t_{2}\right)
$$

Figure 2 represents 3D drawing of the power hacksaw machine, while Figure 3 is an autographic view of the power hacksaw machine designed in this study. 


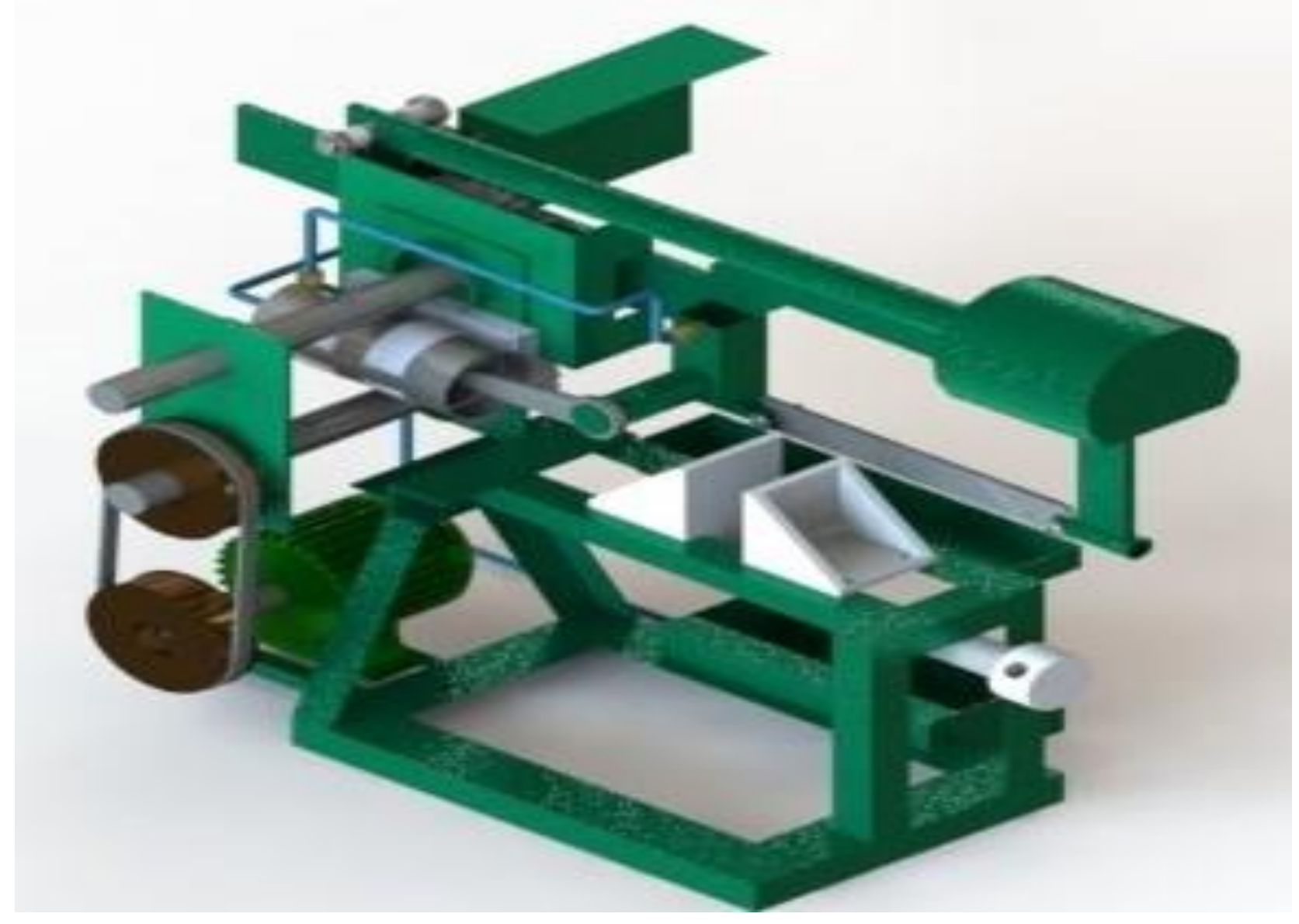

Figure 2: 3D drawing of the power hacksaw machine

\subsection{Working Principles of Power Hacksaw}

The Power hack saw has been modified with a cooling mechanism incorporated into it as shown in Figure 2. The power hack saw has a motor at its base connected via a pulley drive to a shaft that holds the driving gear of the gear train. The gear is meshed with a driven gear over three times its size to increase torque and reduce the speed to facilitate control. Connected to the larger gear is the end of the saw handle. The handle has been modified into an extra-long arm. This connection is made possible by two vertical rod welded to the blade. Welded to the gear is a bearing between the two vertical guides. The gear is allowed to accept motion from the motor to rotate 360 degrees resulting in an oscillating motion of the hack saw blade. This causes the blade that is on the other end of the machine to cut anything on its path. The additional weight adds force onto the cutting action and ensures that the saw lade does not change its direction of cut. The cooling mechanism consist of a very small cylinder with very low pressure suction. The cylinder is attached to the static frame cover of the gears. The plunger is attached to the framework of the reciprocating blade. The cylinder consist of two low pressure valves one is connected to the coolant tank or reservoir. While the other is connected to the blade via tubing. The blade has been modified to have a section in its holder that allows the coolant to flow over the blade, the coolant then wets the blade and then the used coolant then pours into the reservoir which is located under the workbench. The coolant is then filtered by a net filter in the reservoir and drawn back into the cylinder where the process is repeated. The reciprocating action of the blade thus becomes the driver of the plunger. When the plunger moves backward (i.e. the bade forward action) the valve to the reservoir opens and the suction pressure draws the coolant into the cylinder, then the forward motion 
of the plunger (backward stroke of the blade) causes the valve to close resulting and the valve to the bade to open, thus pressurising the coolant in the direction of the blade.

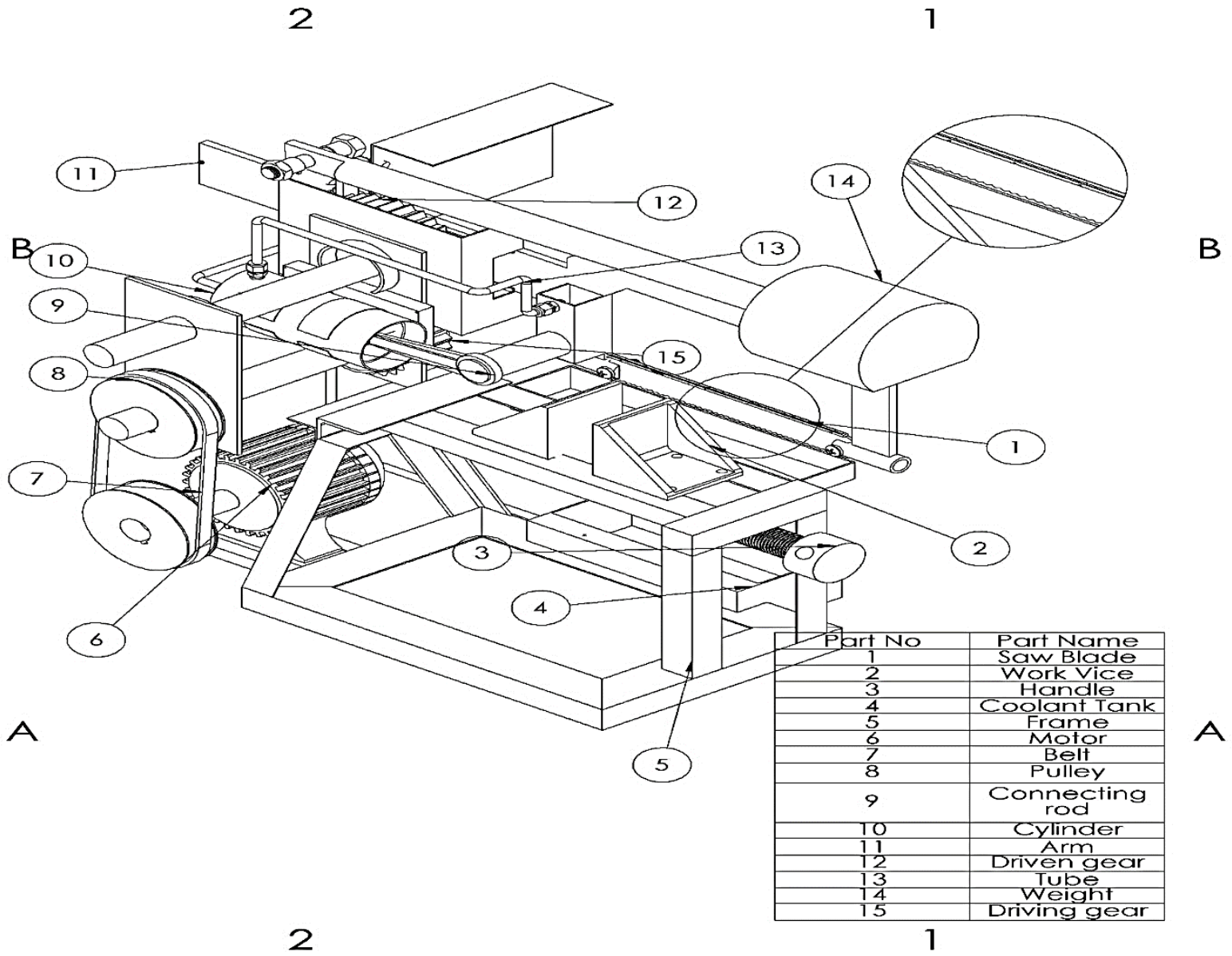

Figure 3: Isometric View of the Power Hacksaw Machine

A cylinder with two gate valves have been added to the frame just behind the cooling mechanism. A piston has been added to the Blade arm which enters into the cylinder. The blade arm has been modified to have a small receptacle blades while the blades have been modified to have a U-channel on top of the saw which has small holes to allow the removal of the fluid. The chip collector has been modified to a fine mesh size filter to allow the liquid to flow to the tank underneath. Tubes connects the tank to one of the valves (Inlet Valve) on the cylinder while another tube connects the other valve (Outlet Valve) to the blade arm receptacle.

\subsection{Operator Guide}

The power hacksaw machine is designed primarily for precision sawing of straight lines (could also be applied in operations involving contours). Laying out the workpiece requires accurate measurement of the thickness in terms of length, breath and height to be cut and indicating cutting position by scribing a line on the stock (workpiece). Prior to mounting of the stock for cutting, the vice should be carefully examined carefully to ensure edge to edge alignment with the hacksaw blade. While typical sawing operation with a power hacksaw is outlined as follows, Table 2 represents the troubleshooting associated with a given power hacksaw machine; 
i. Place a machinist's square against the blade and the stationary vice jaw, and adjust the jaw at an angle of $90^{\circ}$ to the blade. If the workpiece is to be cut at any angle other than $90^{\circ}$, loosen the vice and swivel it to the desired angle, using a protractor to measure the angle.

ii. Select hacksaw blade of proper length for the machine and proper pitch for the specified workpiece to be cut.

iii. Mount the hacksaw blade such that the teeth points downward and toward the motor end of the hacksawing machine.

iv. Examine the alignment of the vice and hacksaw blade and position the workpiece in the vice.

v. Ensure that the workpiece is firmly held by the vice

vi. Examine the stroke of the hacksaw machine and adjust if required.

vii. Adjust hacksawing machine frame and the sawing blade through one cycle (forward stroke and backward stroke) by hand to examine the blade clearance at each end of the workpiece.

viii. Readjust the position of the vice if necessary.

ix. Ensure that the hacksaw blade is well positioned about 1/4 inch above the workpiece and set the feed control to its lightest feed setting.

x. Ensure that the hacksaw machine is properly set to desirable speed.

xi. Start the hacksaw machine and allow the blade to feed slowly into the workpiece for about $1 / 4$ inch.

xii. The feed should be readjusted to whatever capacity the material will stand for proper cutting.

xiii. Allow the hacksaw blade to cut completely through the workpiece.

Table 2: Trouble Shooting of Power Hacksaw Machine

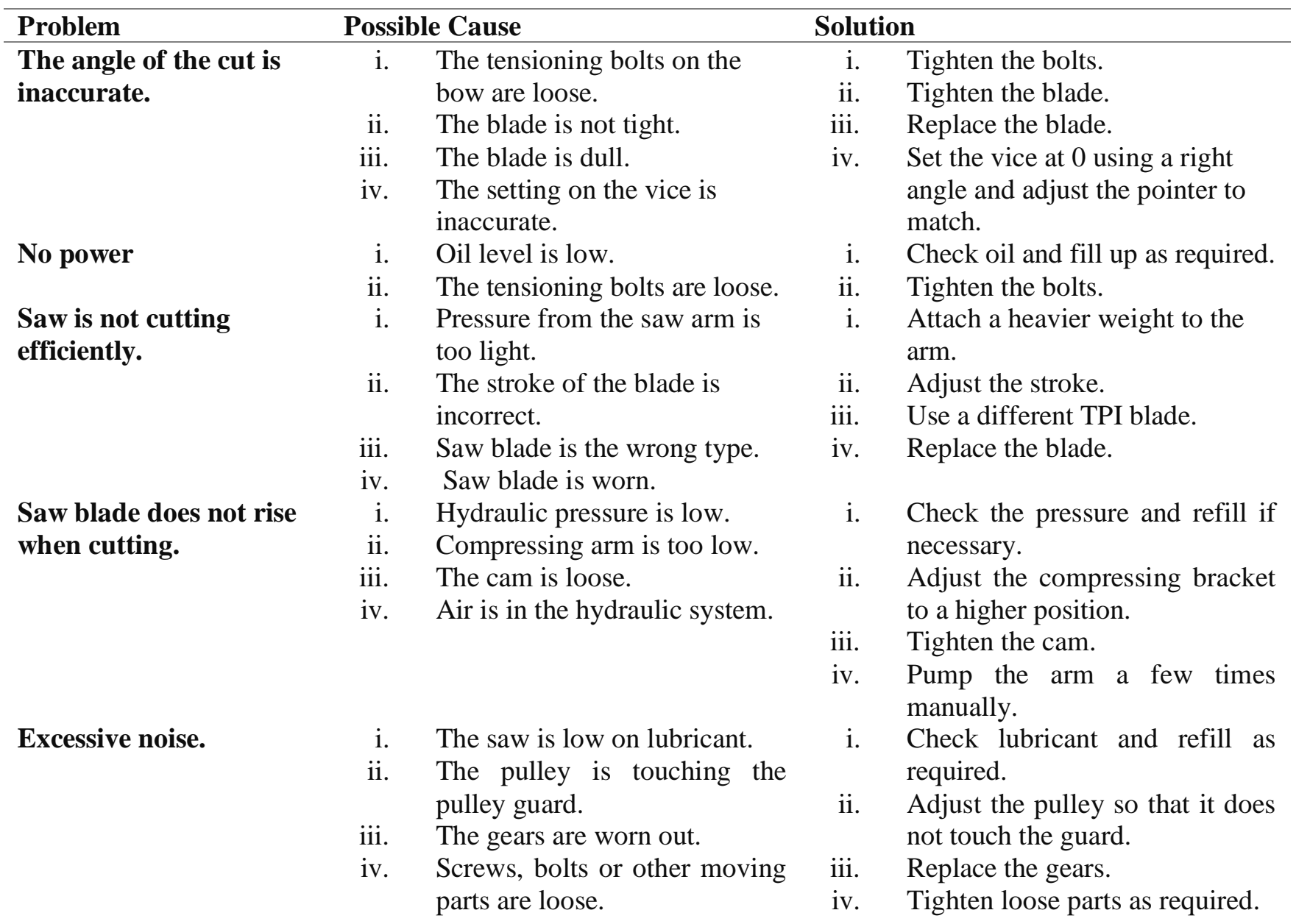


Coolant delivery is weak. i. Sediment may have collected i. Clean the cooling tank. in the cooling tank

\section{RESULTS AND DISCUSSION}

Considering the power rate ( $4 \mathrm{hp}$ ) of the motor calculated earlier, measured mass of timber and the total time at which each mass of timber was cut; the Specific Mechanical Energy (SME) was determined using equation (24);

$$
\text { SME }=\frac{\text { Power }(p) \times \text { Time }(t)}{\operatorname{Mass}(m)}
$$

Similarly, considering the SME, the measured mass of each timber and the total time employed for each cutting operation, the machine cutting speed was determine using equation (25);

$$
\text { Cutting Speed }=\frac{60 \times \text { SME } \mathrm{x} \text { Mass }}{\text { Time }(t)}
$$

The results obtained from manual and automatic cooling hacksaw machine is tabulated in Table 3 , and Figures 4-6 are graphical representation of the results obtained from manual and automatic cooling hacksaw machine.

Table 3: Results obtained from Manual and Automatic Cooling Hacksaw Machine

\begin{tabular}{lllllllll}
\hline & \multicolumn{4}{l}{ Manual Cooling Hacksaw Machine } & \multicolumn{4}{l}{ Automatic Cooling Hacksaw Machine } \\
\cline { 2 - 8 } $\mathrm{S} / \mathrm{N}$ & Mass & Time $(\mathrm{s}) \mathrm{t}_{1}$ & $\begin{array}{l}\text { SME } \\
(\mathrm{kj} / \mathrm{kg})\end{array}$ & $\begin{array}{l}\text { Cutting } \\
\text { Speed }(\mathrm{rpm})\end{array}$ & $\begin{array}{l}\text { Mass } \\
\left(\mathrm{M}_{2}\right) \mathrm{kg}\end{array}$ & $\begin{array}{l}\text { Time }(\mathrm{s}) \\
\mathrm{t}_{2}\end{array}$ & $\begin{array}{l}\text { SME } \\
(\mathrm{kg} / \mathrm{kg})\end{array}$ & $\begin{array}{l}\text { Cutting } \\
\text { Speed }(\mathrm{rpm})\end{array}$ \\
\hline 1. & 3.8 & 30 & 35.5 & 269.8 & 3.8 & 17 & 20.1 & 269.6 \\
2. & 4.2 & 34 & 36.4 & 269.7 & 4.2 & 19 & 20.6 & 273.2 \\
3. & 4.5 & 37 & 37 & 270 & 4.5 & 22 & 22 & 270 \\
4. & 4.7 & 40 & 38.2 & 269.3 & 4.7 & 24 & 22.9 & 269.1 \\
5. & 5 & 43 & 38.7 & 270 & 5 & 27 & 24.3 & 270 \\
6. & 5.2 & 45 & 38.9 & 269.7 & 5.2 & 31 & 26.8 & 269.7 \\
7. & 5.4 & 48 & 40 & 270 & 5.4 & 33 & 27.5 & 270 \\
8. & 5.7 & 50 & 39.5 & 270.2 & 5.7 & 37 & 29.2 & 270 \\
9. & 5.9 & 52 & 39.6 & 269.6 & 5.9 & 40 & 30.5 & 270 \\
10. & 6.2 & 55 & 39.9 & 269.9 & 6.2 & 43 & 31.2 & 270 \\
11. & 6.5 & 57 & 39.5 & 270.3 & 6.5 & 46 & 31.8 & 269.6 \\
12. & 6.8 & 60 & 39.7 & 270 & 6.8 & 49 & 32.4 & 269.8 \\
13. & 7 & 63 & 40.5 & 270 & 7 & 53 & 34.1 & 270.2 \\
14. & 7.3 & 67 & 41.3 & 270 & 7.3 & 56 & 34.5 & 269.8 \\
15. & 7.6 & 72 & 42.6 & 269.8 & 7.6 & 60 & 35.5 & 269.8 \\
16. & 7.8 & 75 & 43.3 & 270.2 & 7.8 & 62 & 35.8 & 270.2 \\
17. & 8 & 78 & 43.8 & 269.5 & 8 & 65 & 36.5 & 269.5 \\
Ave. & 5.9 & 53 & 42 & 269 & 5.9 & 40 & 29 & 270 \\
\hline
\end{tabular}




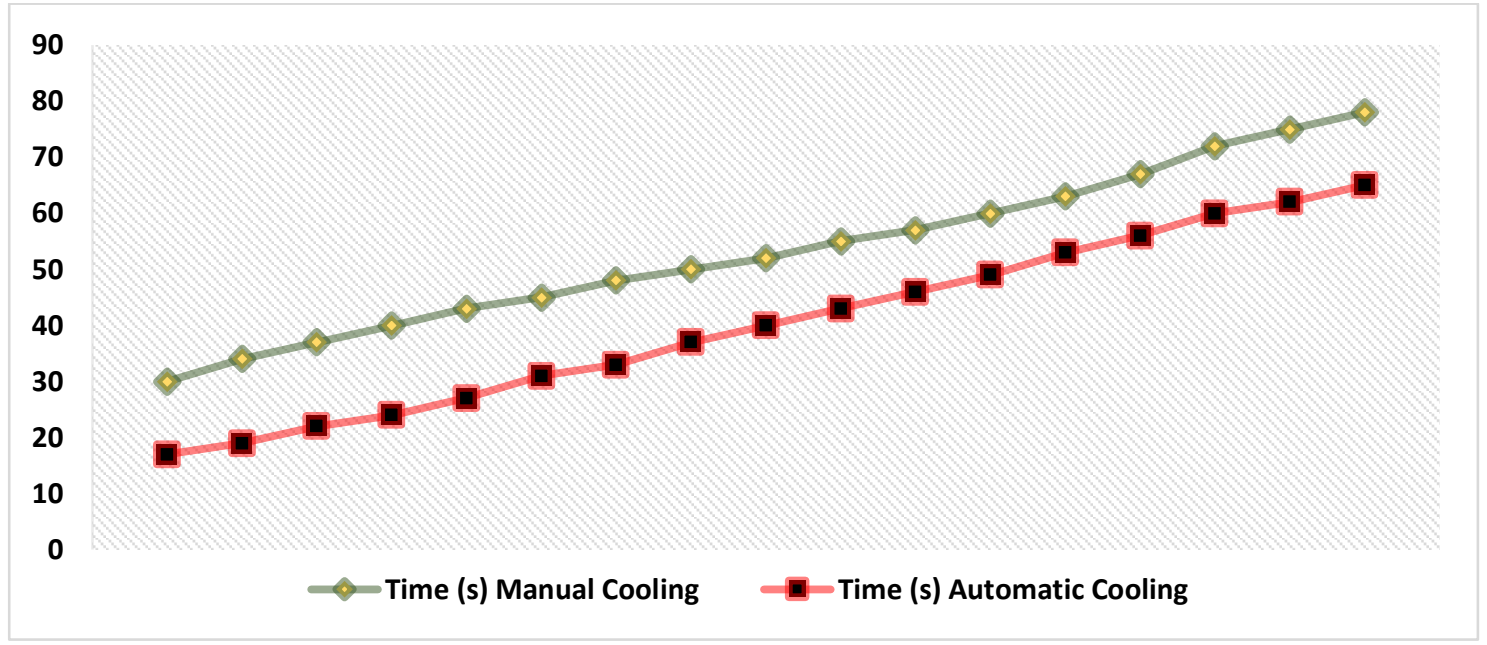

Figure 4: Graph of manual cooling time Vs automatic cooling time of the hacksaw machine

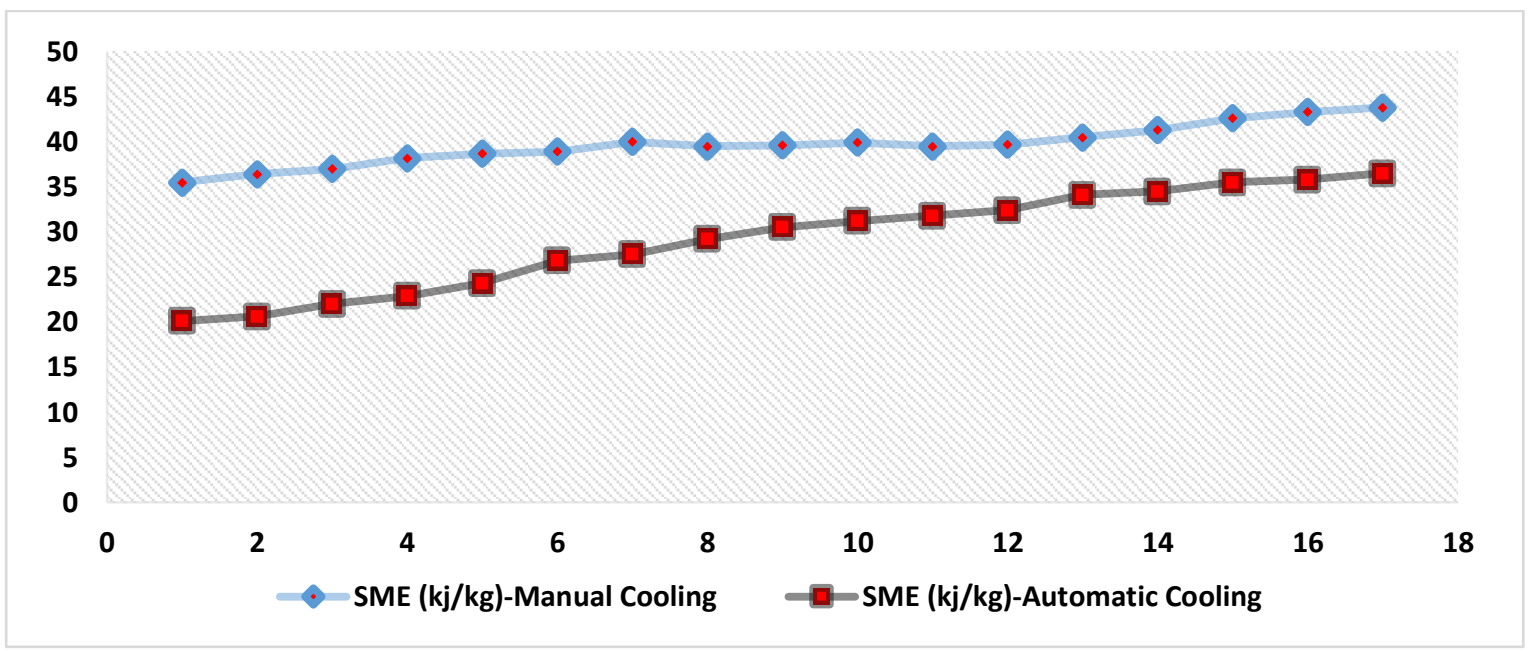

Figure 5: Graph of SME for manual cooling Vs SME for automatic cooling of the hacksaw

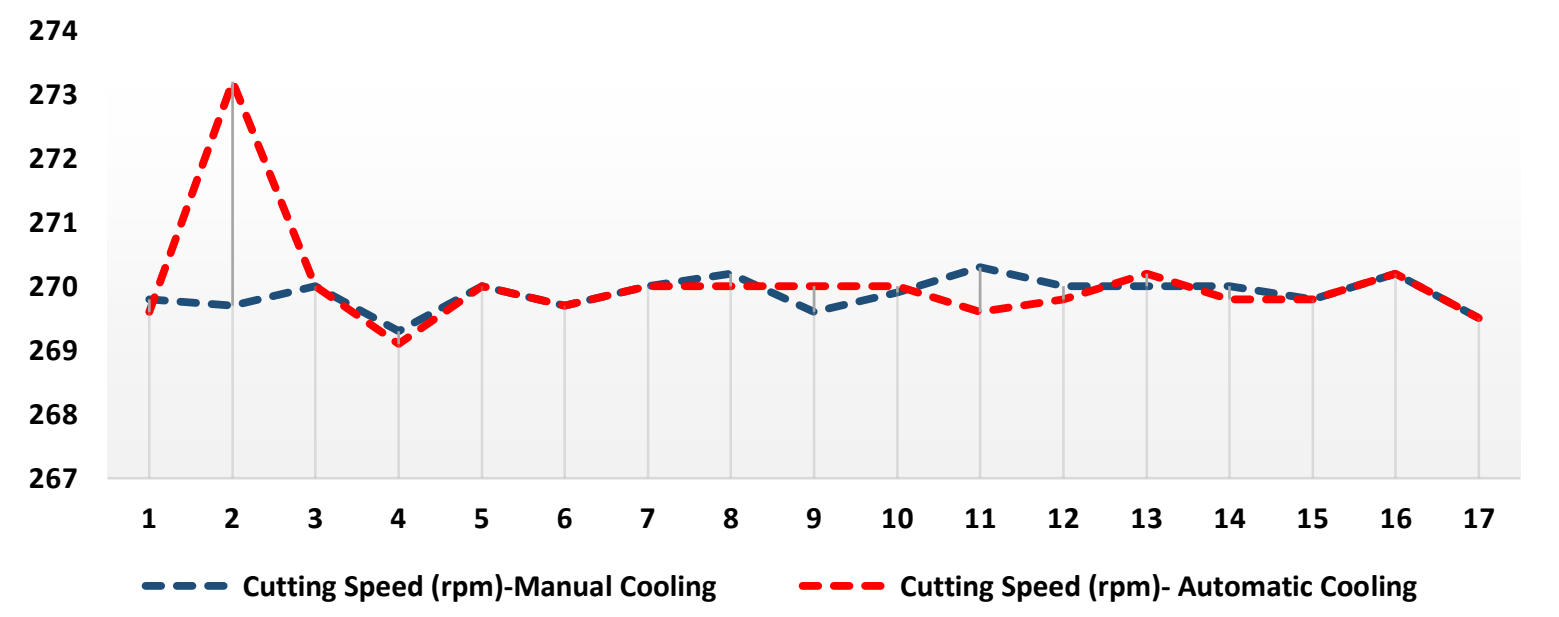

Figure 6: Cutting Speed of Manual Vs Cutting Speed of Automatic Cooling Hacksaw 
Incorporated in the machine is a cylinder with two gate valves. Movement of the sawing blade led to the movement of the piston in the cylinder. Therefore, as the piston moved towards its Bottom Dead Centre (BDC) on the forward movement of the blade, the gate valve connected to the tank opened and a suction pressure was created which draws the liquid coolant into the cylinder. When the blade began to move backwards, the forward movement of the piston to its Top Dead Centre (TDC) caused the valve to close and the other valve to open, thus pumping the liquid through the tube to the receptacle. The coolant then flows through to the sharp zigzag teeth on the blade. On reaching the end, it flow out through the openings and passing through the filter back to the tank and then recirculates again.

Result shown in Figure 4 indicates that the designed automatic cooling power hacksaw machine in this study is more efficient in terms of time savings than the manual cooling power hacksaw machine in a local sawmill. This implies that if less time is consumed for the cutting process, more energy will be conserved for longer duration operation. This can be observed in Figure 4 and 5, where the operational time and SME of the manual cooling power hacksaw machine was quite higher compared to the automatic cooling power hacksaw machine designed in this study. In terms of the cutting speed, the automatic cooling power hacksaw machine speed was slightly higher than the manual cooling power hacksaw machine as shown in Figure 6. To improve cutting speed of the power hacksaw, trade-offs may be required in terms of power input to the motor (voltage and current) and power output from the motor (torque and speed). Therefore, maintaining a constant voltage may only increase the current, and increasing the current can only result at increasing torque (and the total power being supplied to the system), whereas, increasing the voltage can cause increase in the motor speed which is further translated to reciprocating speed of the power hacksaw machine.

Conclusively, it was observed that the cutting speed increased tremendously when the belt was placed on the smaller pulley wheel (driver) of the motor, whereas, placing the belt on the larger pulley wheel (driven) resulted in a reduced cutting speed. However, the cutting speed for a typical power hacksaw can also be reduced by incorporating a reduction gear mechanism (incorporating a speed changing mechanism) to drive the motor output shaft.

\section{CONCLUSION}

The relevance of power hacksaw machine to manufacturing and production industries cannot be over emphasized, as cutting of metals, wood and other materials is required in almost every task. However, automatic cooling hacksaw machines such as the one designed in this study offers more benefit (in terms reduction in cutting time and specific mechanical energy of the machine, cooling hacksaw machine) than manual cooling hacksaw machine. This is evidence in the results obtained in this study where the following benefits were achieved;

i. The power hacksaw machine designed with coolant compartment yielded higher productivity (in terms of cutting) in a shorter time frame compared to power hacksaw machines in local sawmills without coolant.

ii. Apart from the reduction in cutting time, the machine offered huge reduction in labour, energy requirement and prevention of downtime.

iii. Efficiency of the cutting blade applied in the automatic cooling power hacksaw machine was higher with less heat compared to that of the blade observed in local sawmill.

\section{REFERENCES}

[1] Verma, S. and Raza, P., "Four Way Hacksaw Machine-A Review", International Journal of Advance Research and Innovative Ideas in Education, 2(3), 36-41, 2016.

[2] Quadri, S. A., Shaik, A., Shoaib, M., Khavi, M. A. and Farooqui, G. O., "Solar Operated WoodCutter", International Journal \& Magazine of Engineering, Technology, Management and Research, 4(3), 569-578, 2017. 
[3] Sabariananda, D. V., Siddhartha, V., Krishnana, B. S. and Mohanraj, T., "Design and Fabrication of Automated Hacksaw Machine", International Journal of Innovative Research in Science, Engineering and Technology, 3(2), 261-269, 2014.

[4] Mathivanan, S. Ajith, S. Gobinath, J. Illaya Bharathi, S. K. and Kingsly F. A., "Design and Fabrication of Advanced Pneumatic Hacksaw Cutting Machine, Bonfring" International Journal of Industrial Engineering and Management Science, 6(4), 182-185, 2016.

[5] Lipcha, B., Kadam, A., Gadakh, S., Yadav, A. and Pathan, F. U., "Rectification of Power Hacksaw Machine", International Journal of Advanced Technology in Engineering and Science, 4(3), 351-356, 2016.

[6] Biswas, A., Salunke, A. Patil, A. and Patil, A., "Review on Multiway Hacksaw Machine", International Journal of Innovative and Emerging Research in Engineering 4(3), 92-96, 2017.

[7] Kshirsagar P. R., Rathod N. J., Rahate P. P., Halaye P. P. and Surve S. S. (2015) Theoretical Analysis of Multi-Way Power Hacksaw Machine, International Journal of Research in Advent Technology, 3(4), 37-40.

[8] Sibabrata, M., Anil, P., Chaitanya, A., Dharamdeep, R., PrashantKumar, S. and Sunil, L., "Multi-arm Power Hacksaw Machine", International Journal of Engineering Studies and Technical Approach, 3 (4), 1-6, 2017.

[9] Chaitanya, P., "Design and analysis of Power hack Saw attachment to a Centre Lathe", International Journal of Engineering Research and General Science, 4,(3) 752-765, 2016.

[10] Khaja M. G. and Babu, T. J., "Fabrication of pedal powered hacksaw machine", International Journal of Scientific Development and Research, 1(8), 260-268, 2016.

[11] Wisley, F. S., Anselmo, E. D. and Alisson, R. M., "Application of cutting Fluids in Machining Processes", Journal of the Brazilian Society of Mechanical Sciences, 23 (2), 2001.

[12] Jayal, A. D. and Balaji, A. K., "Effects of Cutting Fluid Application on Tool Wear in Machining: Interaction with Tools-coatings and Tool Surface Features", Journal of Wear, 267(9-10), 1723-1730, 2009.

[13] Singh, R. and Bajpai, V., "Coolant and Lubrication in Machining, Handbook of Manufacturing Engineering and Technology", pp 1-34, Springer London, 2014.

[14] Danielson, J. D. and Schajer, G. S., "Saw Blade Heating and Vibration Behaviour in a Circular Gang Edger", $3^{\text {rd }}$ International Conference on Sawing Technology, October, 14-16, San Francisco, Wood Machining Institute, 117-136, 1993.

[15] Benedicto, E., Carou, D. and Rubio, E. M., "Technical, Economic and Environmental Review of the Lubrication/Cooling System Used in Machining Processes", Advances in Material and Processing Technologies Conference, Procedia Engineering, 184, 99-116, 2017.

[16] Parmar, N., Nitin, G., and Bhrijen, R., "A Review on Design and Fabrication of Four Power Adjustable Stroke Hacksaw", Imperial Journal of Interdisciplinary Research, 3(5), 1122-1125, 2017.

[17] Sreejith, K., Aravind, K., Davis, K., Farish, K. A. and Johnson, G., "Experimental Investigation of Pedal Driven Hacksaw", Research Inventory: International Journal of Engineering and Science, 4(7), 1-5, 2014.

[18] Kumar, K. V., Abilaash, M. B. and Chakravarthi, P., "Double Acting Hacksaw Machine", International Journal of Modern Engineering Research, 7(3), 19-33, 2017.

[19] Budynas, R. G. and Nisbett, J. K., "Shigley's Mechanical Engineering Design, Eighth Edition", McGraw-Hill, New York, NY 10020, ISBN: 978-007126896-7, 2008.

[20] Maekawa, K., Obikawa, T., Yamane, Y. and Childs, T. H., "Mechanical Design $2^{\text {nd }}$ Edition", Butterworth-Heinemann, Oxford, UK, ISBN: 9780550657716, 2003.

[21] Eastop, T. D. and McConkey, A., "Applied Thermodynamics for Engineering Technologist", Fourth Edition, Pearson Education Ltd. ISBN:8178085577, 2004. 